\title{
Los discursos de defensa femeninos en la narrativa española del siglo xv
}

\section{Female Defense Discourses in 15th-Century Spanish Narrative}

\author{
TATIANA Bedoya \\ Universidad Nacional de Colombia \\ stbedoyam@unal.edu.co
}

\begin{abstract}
RESUMEN
Desde la Antigüedad se construyeron modelos femeninos que clasificaban a las mujeres en "buenas" y "malas", teniendo en cuenta si encajaban o no con los valores socialmente legitimados. Durante el siglo Xv se desarrollaron en Europa debates acerca del papel de la mujer en la sociedad — querelles des femmes - en el que distintos autores tomaron la posición de "defensores" o "maldicientes". Sin embargo, la división que se propone en estos debates, mediante la cual se obtienen discursos de defensa femeninos, resulta ser aparente y responde más bien a una necesidad retórica, debido a que los presupuestos ideológicos, a partir de los cuales se desarrollaban estos discursos, imposibilitaban la creación de una defensa legítima. A partir de esta hipótesis, el artículo se propone el análisis de algunas de estas "defensas femeninas" en España, tanto aquellas que se construyeron con fines retóricos (Triunfo de las donas) como aquellas que se desarrollaron en la ficción sentimental del siglo xv (Grimalte y Gradissa y Grisel y Mirabella).
\end{abstract}

Palabras Clave: Grimalte y Gradissa, Grisel y Mirabella, Juan de Flores, Juan Rodríguez del Padrón, querelle des femmes, Triunfo de las donas

\begin{abstract}
From ancient times, female models were constructed that classified women as "good" and "bad", considering how well they fit on the values socially legitimated. During the fifteenth century, debates about the role of women in society - querelles des femmes - took place in Europe. There different authors took a position as "defenders" or "attackers". However, the proposed division in those debates, through which defense discourses for women were obtained, results to be apparent and responds better to a rhetoric necessity. The creation of legitimate defense is impossible due to the ideological presuppositions from which those discourses were developed. From this hypothesis, the paper proposes the analysis of some of these "female defenses" in Spain, both those constructed with rhetoric proposes (Triunfo de las donas) and those developed in the sentimental fiction of the fifteenth century (Grimalte $y$ Gradissa and Grisel y Mirabella).
\end{abstract}


KeYwords: Grimalte y Gradissa, Grisel y Mirabella, Juan de Flores, Juan Rodríguez del Padrón, querelles des femmes, Triunfo de las donas

FECHA DE RECEPCIÓN: 08/01/2020

Fecha De ACEPTACión: 11/03/2020

Donzella, ¿qué cosa es la mujer?

La donzella le respondió: "Arca de mucho bien y de mucho mal, imagen del hombre, bestia que nunca se harta"

Historia de la doncella Theodor

$\mathrm{E}$ n la Antigüedad se construyeron distintos símbolos femeninos a través, sobre todo, de los relatos mitológicos. En la mitología, figuras como la de Medusa nos presentaban una mujer caracterizada por un poder excepcional que le permitía convertir en piedra a todo aquel que la mirara a los ojos. También en la mitología griega se recrean figuras como las Erinias, quienes representaban el poder de la venganza y el castigo, o las Moiras, quienes se encargaban del destino de todos los hombres. Sin embargo, la fuerza - y a la vez el temor - que representaban tales figuras femeninas solo eran posibles en la mitología porque, tal como afirma Staley, "only in myth can women find among the traditions of European culture a 'somewhere else' that includes them amidst all which the Greeks regularly excluded" ("Feminism Myth", 217). En la realidad social de la Antigüedad, las mujeres no ejercían tal poder y el temor de lo femenino se traducía en una constante opresión y silenciamiento; es decir que, más allá de una inferioridad "natural" de la mujer, lo que determinaba la actitud de los hombres frente a las mujeres en la Antigüedad era precisamente el temor a su condición. No obstante, tal como propone Madrid, sería muy limitado atribuir ese temor a una cuestión psicológica solamente, pues responde fundamentalmente a un temor sobre la organización social de la polis que, por "derecho", se le concedió al hombre solamente:

El temor que subyace en estas construcciones mentales no parece ser tanto la proyección de un miedo inconsciente e intemporal, sino que tiene que ver con los papeles socialmente asignados a varones y mujeres, con las relaciones existentes entre los dominios de la vida pública y privada y con la jerarquización establecida entre ambos (La misoginia, 23). 
Por ejemplo, al pensar en los símbolos femeninos que desarrollaría posteriormente el cristianismo, nos encontramos con figuras como las de Eva que, además del temor ya mencionado, desarrolla el motivo de la culpabilidad, y María que personifica un modelo femenino inexistente. A través del mito de la creación, el cristianismo subordinó la posición de la mujer respecto al hombre, en la medida en la que Eva fue creada después de Adán, a partir de una de sus costillas, con la función principal de acompañante. De acuerdo con lo que menciona Archer, no es solo una cuestión de subordinación "social”, sino que Eva se caracteriza también por ser moralmente inferior a Adán, pues “su 'imperfección' adquiere una dimensión moral según la cual Eva es la puerta y vía del pecado que tanto sufrimiento ha traído al mundo" (Misoginia, 26). Por su parte, María no solo es símbolo de la subordinación de la mujer al hombre, sino que, a través de ella, se representa una idea de "superación" del pecado y ascenso espiritual a través de la virginidad. El poder sexual femenino al que temían los griegos queda subordinado a la tarea de reproducción y maternidad, estado al cual debía aspirar toda mujer, a partir de los valores morales que instaura la religión cristiana. Por supuesto, estos dos símbolos situaban a la mujer en una posición contradictoria e insalvable: primero, cargaba consigo una culpa intrínseca por una tendencia hacia el pecado y, segundo, se le exigía un estado de castidad y obediencia superior al del hombre. Estas figuras contradictorias propias del cristianismo, si bien responden a otro contexto social y cultural, no parecen alejarse del temor que suscitaba lo femenino en la Antigüedad. Todo lo contrario: hubo un interés en buscar fundamentos biológicos que permitieran justificar la subordinación de la mujer (quizá para convencerse de que aquel temor no tenía fundamentos) y también hubo un interés en construir modelos simbólicos benevolentes y pasivos, modelos que se alejaran completamente de esa fuerza "pecadora”.

Durante la Edad Media, la inferioridad biológico-moral de la mujer y la posibilidad de superación mediante la castidad y la maternidad se reflejan en distintas tradiciones: por un lado, se retoma el tópico aristotélico sobre la imperfección natural de la mujer y el supuesto de que la mujer es cuerpo mientras el hombre es alma; y, por el otro, en los ambientes cortesanos se desarrolla un tópico sobre el amor, el amor cortés, que idealiza a la mujer, incluso hasta la divinidad. A través de los argumentos de Aristóteles y Galeno se desarrolla toda una línea "médica" sobre la imperfección biológica de la mujer y se llega incluso a condenar el matrimonio (misogamia); ejemplo de ello es el tratado Liber de nuptiis de Teofrasto (c. 372-288). Asimismo, valores como la honra se convirtieron en "el deber ser" de las mujeres. Este tipo de tradiciones permitió que se empezara a hablar de "buenas" y de "malas" mujeres y que 
se desarrollaran debates sobre el lugar de la mujer dentro de la sociedad y las características filosóficas que caracterizaban a una y a otra.

Que en estos debates se hable de "buenas" y "malas" mujeres permite, también, que se construyan posiciones "en contra" y "en pro" de las mujeres con sus distintas valoraciones. Precisamente durante el siglo XV se crearon discursos que "defendían" y "maldecían" de las mujeres, utilizando todas las tradiciones filosóficas, biológicas y literarias que hemos mencionado someramente. Es el caso, por ejemplo, de textos como el Triunfo de las donas de Juan Rodríguez del Padrón o Defensa de virtuosas mujeres de Diego de Valera. Estos discursos, construidos en forma de debate, constituyeron lo que se conoce en Europa como la querella de mujeres, lo que ha llevado a algunos críticos a hablar de misoginia y filoginia en el análisis de dichos debates. Sin embargo, de acuerdo con lo que apunta Vélez, estas disputas responden, sobre todo, a una tradición retórica: "pues casi siempre se toma en forma de debate o de disputatio de carácter argumentativo el ataque o la defensa de las donas, lo que deja claro que tiene una forma marcadamente retórica" (La defensa, 23). Así, en este contexto, en vez de autores misóginos y filóginos (términos considerados anacrónicos) conviene mejor hablar de maldicientes y defensores.

Aunque estos discursos responden a ciertos intereses retóricos, es claro que están en constante diálogo con las condiciones sociales de la época. Por ejemplo, el Jardín de nobles doncellas de fray Martín de Córdoba está dedicado a la princesa Isabel de Castilla con el fin de que tenga en cuenta los principales defectos de las mujeres que debe evitar si quiere que su gobierno salga bien. Aunque el texto se construya como un manual en el que se retomen los principales defectos de las mujeres, el fin último del texto es que la princesa Isabel pueda superar estos defectos, porque en el fondo hay un apoyo político a su gobierno. En este mismo sentido, es importante analizar cómo estos debates empiezan a hacer parte de distintos géneros ficcionales de la época (por ejemplo, en el caso de Cárcel de amor de Diego de San Pedro o Grisel y Mirabella de Juan de Flores) y cómo se van transformando de acuerdo con el fin del texto literario - y la consolidación de un género como la ficción sentimental-y las intenciones de cada autor.

En ese orden de ideas, el objetivo de este trabajo es analizar cómo estos debates, en principio filosóficos y retóricos, empiezan a hacer parte de los distintos géneros ficcionales de la época y cómo se pueden poner en diálogo con otros discursos que, si bien no cuentan con las mismas características de estos debates filosóficos, sí ensayan una defensa de las mujeres a partir de otros elementos. Estos últimos discursos están relacionados con personajes, sobre todo femeninos, que, frente a una acusación personal (reproche frente a 
comportamientos específicos, por ejemplo), construyen todo un entramado argumental que pretende defenderlas. La diferencia entre ambos discursos de defensa estaría en que los primeros están construidos con una intención más bien retórica, mientras que los segundos tendrían un fin narrativo, con impacto en el desarrollo de los personajes.

A través del análisis de aquellas disputationes, construidas con un fin claramente retórico (Triunfo de las donas de Juan Rodríguez del Padrón), incluyendo las que se insertan en los géneros ficcionales (Grisel y Mirabella de Juan de Flores), en contraposición con aquellos discursos narrativos creados por los personajes femeninos (Grimalte y Gradissa de Juan de Flores), pretendemos cuestionar las categorías de defensa y maldecir, pues el hecho de que algunos estén concebidos como defensa propiamente o que estén dedicados a mujeres específicas no los hace un texto o un discurso de defensa, teniendo en cuenta que los presupuestos ideológicos de la época hacían muy difícil la creación de una defensa verdadera. Para esto es importante, entonces, considerar cuáles eran los propósitos en la construcción de los distintos discursos de defensa de las mujeres en contextos específicos de producción literaria.

El análisis de tales discursos se enmarca, por supuesto, no solo en un interés por cuestionar lo que se ha entendido como defensa y maldecir en el contexto de la querella de mujeres, sino que el interés es, particularmente, profundizar en las distintas ideas que se desarrollaban en la época sobre la mujer y cómo esas distintas voces pueden mostrar la complejidad de ese carácter femenino y la complejidad que la imagen de la mujer representaba en la época. Teniendo en cuenta que los símbolos a los que nos hemos referido hasta aquí se han perpetuado a través de la literatura y la mitología, es importante analizar también la relación de los discursos a estudiar con esta tradición literaria, con el fin de rastrear sus transformaciones y, así, tener pistas sobre el papel y la representación de la mujer en la época. En ese sentido, es necesario tener en cuenta que en épocas en las que las mujeres no representaban una voz cultural, esto es, una voz que tuviera una influencia establecida en la construcción y desarrollo de una sociedad, conviene detenerse en aquello que sobre ellas se escribía para demostrar que, aunque acalladas, su importancia en la sociedad era fundamental.

Así, en un primer lugar, se tratarán algunos símbolos femeninos desarrollados a través de los escritos clásicos y medievales más representativos que dan paso a la querelle des fermmes en España. A partir de este contexto, se examinarán algunos pasajes específicos del corpus seleccionado, teniendo en cuenta la distinción que ya se mencionó (discursos de defensa filosóficos y narrativos). Este análisis se hará a partir de dos criterios: el primero, será 
un criterio retórico, es decir, se analizarán los discursos como ejercicios filosóficos con características propias de la argumentación retórica, teniendo en cuenta la tradición ciceroniana. El segundo criterio tendrá en cuenta el contexto histórico y social de la época con el fin de analizar el surgimiento de estos discursos a la luz de su contexto.

\section{EL MITO DE LA MUJER: \\ CONSIDERACIONES SOBRE LO FEMENINO}

La construcción de lo que es la mujer en una sociedad se da, no solo a partir de lo que hace y piensa la mujer misma, sino también a partir de lo que el 104 hombre piensa e impone, pues las distintas caracterizaciones del género son construidas a lo largo de la historia. En ese sentido, tanto los testimonios propios de las mujeres como los de los hombres tienen un valor fundamental en esta construcción. Hay que tener en cuenta que, en la época, la voz de la mujer, si aparece, está representada de manera indirecta en la mayoría de ocasiones, tal como lo señala Lacarra ("Notes on feminism", 14-22). La autora advierte que en el estudio de la mujer española medieval no basta con encontrar un texto escrito por una mujer para entender su posición real frente a la sociedad, pues su punto de vista también está inmerso en los presupuestos que se le han impuesto y, además, como señala Kaplisch, porque "sus imperiosas presiones han marcado, quizá más que en ningún otro periodo, el lugar asignado a las mujeres en la sociedad" ("Introducción").

Los discursos que podemos enmarcar dentro del contexto de la querelle des femmes se construyen a partir de ideas comunes sobre la mujer, estereotipos que se fueron consolidando con el paso del tiempo y que fueron retomados en medio del auge de los discursos sobre la condición femenina. Si bien, tal como considera Archer, "the localized context in which each of the texts is written ensures that the combination of common ideas about women they each contain - that is, the inclusion and exclusion of such ideas - is nearly always unique" (The Problem, 34), sí pueden identificarse características, atribuidas a las mujeres, consideradas prácticamente inmodificables, naturales. De hecho, la necesidad creciente de apoyar los presupuestos sobre la mujer en argumentos biológicos puede entenderse como un afán por institucionalizar tales presupuestos y convertirlos en verdades irrefutables. La idea de la mujer se convierte, así, en un mito que "es solamente la 'marca' que el opresor impone sobre los oprimidos” (Wittig, El pensamiento, 34), esto es, un discurso que le permite a la clase dominante (en este caso los hombres) seguir 
dominando. Al respecto, Millán afirma que: "el relato del mito busca la coherencia para solucionar un problema social, cultural y estructural que tiene que ver con la vertebración de las instituciones y con las normas que regían la vida de los ciudadanos" (“Amazonas", 120), por tanto, el mito de la mujer intenta explicar su posición subordinada en la sociedad y su papel inferior respecto al hombre.

Aunque las mujeres que son caracterizadas a través de estos debates del siglo XV son producto de ideales específicos construidos por el sistema patriarcal, estos discursos no parecen alejarse de la realidad social, sino que pueden llegar a configurarla. Si tenemos en cuenta el planteamiento de Wittig según el cual la opresión física de la mujer se origina "en el campo abstracto de los conceptos, por las palabras que los formalizan” (El pensamiento, 17), los discursos de defensa o vituperio están en una constante dialéctica con la realidad social de la época: la realidad se configura a través de los discursos y los discursos perpetúan un orden social y político específico. En este sentido, conviene detenerse en los distintos ideales y símbolos que configuraron la querelle des femmes y que, al mismo tiempo, consolidaron el mito de la mujer medieval. Al retomar estas características, se puede determinar el propósito de los discursos que conforman el corpus elegido, debido a que "most writers, when faced with the task of defining the nature of women, allude only to those aspects which are essential to their particular needs; they regularly avoid entering into the subject in more detail than the aims of the text require" (Archer, The Problem, 204). Estos discursos, aunque con un propósito retórico, no son neutros y es de nuestro interés examinar las relaciones que se pueden establecer entre estos discursos y la configuración ideológica de la época, en concordancia con lo que considera Lacarra respecto a los discursos del cuerpo en la época medieval:

De ahí que se considere fundamental comprender sus estructuras ideológicas como construcciones discursivas políticamente cargadas y que se insista en analizar cómo se formulan las diversas identidades sexuales con sus complejidades y contradicciones, según las relaciones de poder, y no simplemente la oposición hombre-mujer ("Notes on Feminist", 74).

Ahora bien, Aristóteles fue el principal precursor de una jerarquización de los roles femeninos y masculinos en la sociedad. En la Política, el autor especifica que el rol dentro del núcleo familiar es distinto para hombres y mujeres: el primero se encarga de adquirir, mientras que el rol de la mujer dentro del hogar se basa en conservar los bienes y las riquezas (Aristot. Pol. 
3.1277b). ${ }^{1}$ Esta diferencia también la encontramos en el Económico de Jenofonte: "Entonces, ya que ambas tareas, las de dentro y las de afuera, necesitan de cuidado y de trabajo, considero que dios creó la naturaleza de la mujer para el cuidado de los trabajos de adentro <y la del hombre para los trabajos de afuera $>$ " (Xen. Ec. 7.22). ${ }^{2}$ Esta separación de roles, basada en el interior y en el exterior, puede entenderse a través de los roles propios de las esferas privadas y públicas. En la Edad Media a la mujer se le atribuyeron cargos más privados, propios del interior, del hogar, mientras que el hombre se movía en la esfera pública, en el exterior: "por un lado, la mujer se aleja de la vida pública y exterior de la comunidad y se esconde en el espacio privado e interior de las casas y de los monasterios; por otro lado, se separa de la exterioridad de su cuerpo y se consagra a la interioridad del alma" (Casagrande, "La mujer 106 custodiada”, 131). Las tareas propias de las mujeres estaban enfocadas, entonces, en ese espacio doméstico, de ahí que su participación en la cultura (en la escritura, por ejemplo) fuera también muy reducida.

Esta división de las tareas femeninas y masculinas - y, por ende, la inferioridad de la mujer en la sociedad - también estaba fundamentada en presupuestos biológicos. Lo femenino, según Aristóteles, se caracterizaba por ser materia $[\hat{v} \lambda \eta]$, mientras que lo masculino era el ser creador [o $\delta \varepsilon \mu$ เovprós] (Arist. GA. 738b 20-21). Aristóteles también justificó la imperfección natural del sexo femenino a través de la temperatura: mientras el macho conserva el calor, la hembra es fría por naturaleza y es, por tanto, una malformación

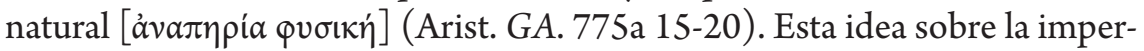
fección biológica de la hembra tuvo tanto auge en la época medieval que se transmitía en los tratados de medicina y ciencia (como por ejemplo De secretis mulierum del Pseudo-Alberto Magno o El tratado de la fascinación o aojamiento de Enrique de Villena).

Aristóteles, mediante sus discursos de carácter científico, consolidó los prejuicios sobre la inferioridad de la mujer y logró convertirlos en verdades eternas, lo que permitía mantener la jerarquía social y esconder la opresión política de la mujer. La fuerza de la argumentación aristotélica fue tal que, hasta hace muy poco, se empezaron a cuestionar estos supuestos biológicos que

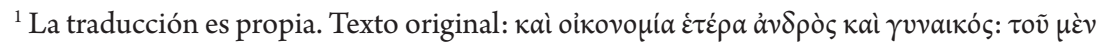

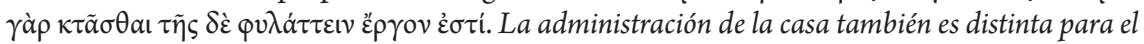
hombre y la mujer: para él es adquirir, para ella guardar los bienes.

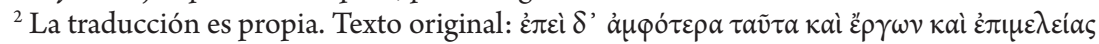

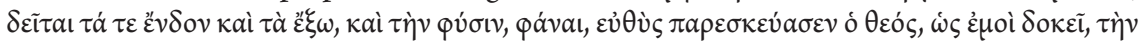

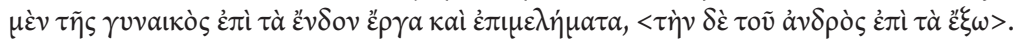


limitaron durante años el carácter femenino. Hoy es posible afirmar que, junto a los símbolos de lo femenino, estas verdades eternas también fueron construcciones sociales creadas para manipular y mantener bajo control a las mujeres. Tal como afirma Wittig: "somos manipuladas hasta tal punto que nuestro cuerpo deformado es lo que ellos llaman 'natural', lo que supuestamente existía antes de la opresión; tan manipuladas que finalmente la opresión parece ser una consecuencia de esta 'naturaleza' que está dentro de nosotras mismas (una naturaleza que es solamente una idea)" (El pensamiento, 32).

En ese sentido, la inferioridad e imperfección biológica de la mujer puede considerarse como parte de uno de los principales mitos, retomados en la querella de mujeres como tópico y argumento central, no solo en los discursos de vituperios en contra de las mujeres, sino también en los discursos de defensa, en los cuales se intentaba demostrar que dicha inferioridad biológica podría utilizarse en favor de las mujeres, como veremos más adelante.

Junto a los argumentos biológicos o "científicos" de Aristóteles que, posteriormente, fueron retomados por Galeno, se encuentran también los presupuestos bíblicos a partir de la creación de Adán y Eva. Como ya hemos señalado, a partir del mito de la creación, la mujer se considera ancilar respecto al hombre: no solo se trata de una inferioridad biológica, sino que, bajo los presupuestos divinos, la mujer debe servir al hombre, de ahí que haya sido creada a partir de una de sus costillas. En la medida en la que el hombre es aquel que nombra a la mujer a través del lenguaje que solo él poseía, "la mujer queda caracterizada como un objeto más" (Vélez, La defensa, 48). El mito de la mujer también se construye a partir de la narración de la expulsión del Paraíso y el pecado original por parte de Eva, lo que da paso a distintas caracterizaciones de lo femenino: se enfatiza la antinomia entre hombres y mujeres, "lo femenino y lo masculino quedan adscritos al talón y la cabeza" ( $L$ a defensa, 49) y la mujer es incapaz de controlarse, tanto en la esfera moral como sexual, por lo cual debe subordinarse al control del hombre, quien se define como superior moralmente. A partir del pecado de Eva, la mujer deberá cargar con culpa para siempre y el hombre deberá estar precavido ante su maldad y deformidad moral incontrolable. Lo anterior puede resumirse en las palabras de Heloísa: “Desdichada yo, que nací para ser la causa de tal crimen! ¡Las mujeres no podrán conducir nunca a los hombres más que a la ruina!" (citado en Olalla, "Bajo el signo", 487).

La maldad inherente de la mujer se contrapone al papel de madre: solo en el momento en el que la mujer se convierte en madre, puede expurgar su pecado, aunque el dolor del parto le vuelva a recordar su culpa. Sin embargo, de acuerdo con lo que señala Olalla, no quiere decir que la religión defienda 
a las mujeres por su capacidad de engendrar, sino que "la mujer es construida ideológicamente por la Iglesia como maldad, mentira, pecado, y siempre remite a Eva. Es la 'madre' la que es construida por la Iglesia como bondad, verdad, salvación y siempre remite a María" ("Bajo el signo”, 487), es decir que la mujer es Eva hasta que se convierte en madre y su signo cambia al de María. Así, a pesar de que la mujer sea mala por naturaleza desde su concepción, puede llegar a superarse a través de la procreación. Nuevamente, esta característica sobre la superación moral de la mujer nos remite a una necesidad de la sociedad de la época que se perpetuaba a través de la procreación de descendientes varones, tarea imposible sin la participación femenina. Esta necesidad de mantener un orden social específico también la encontramos en la institución del matrimonio impuesta por la Iglesia, mediante la cual la mujer pasa del yugo de su padre al yugo del esposo. Esta institución pretende hacerse pasar por natural: "La ley convierte lo arbitrario en intemporal e incuestionable, así que esta división se convierte en una suerte de natural distribución, como si emanara de la propia naturaleza” (Millán, “Amazonas”, 125).

Paradójicamente, durante la querella se retomaron los argumentos de Juvenal, que eran, principalmente, de injuria a la mujer casada. En la sátira VI, Juvenal hace un recuento de todos los vicios de las mujeres e intenta convencer a Póstumo de no casarse. Por ejemplo, leemos en el texto:

Pero si amas ingenuamente a tu esposa, si tu corazón está entregado a ella sólo, agacha la cabeza y prepara tu cuello para llevar el yugo. No encontrarás ni una que respete a quien la ama: bien que ella misma arda de pasión, disfruta torturando al amado, esquilmándolo. De modo que tanta menos utilidad sacará de su mujer el marido cuanto más bueno y deseable sea (Sátiras, 67).

De esta sátira y otros textos de Juvenal se retoman ideas como la de la mujer parlera, el exceso de adornos, el apetito sexual incontrolable y, de ahí, la mujer adúltera y toda la crítica relacionada con la mujer casada. Con las ideas de Juvenal se puede analizar cómo las nociones de imperfección biológica de la mujer permean el entramado moral y consolidan un mito alrededor de los vicios y las virtudes de las mujeres.

Los argumentos biológicos, religiosos y morales que hemos descrito brevemente aquí serán retomados constantemente en la querelle des femmes con distintos propósitos. Retomar estas características comunes que conformaron el mito de la mujer en la época medieval nos permite comprender las contradicciones a las que fueron sometidas. Estas contradicciones se deben, por un lado, al ideal moral que se imponía sobre ellas y, por otro, a la imagen 
que tenían los hombres sobre ellas. Ambas, por supuesto, resultaban ser distintas entre sí: se les exigía seguir el modelo de la virgen, mientras, al mismo tiempo, eran consideradas las hijas de Eva y su pecado. Del mismo modo, estas características permiten examinar los objetivos específicos de este tipo de debates y sus relaciones con el orden social de la época. Aunque los discursos se construyeron a partir de objetivos retóricos, estos discursos también tenían propósitos políticos pues, tal como señala Weiss:

The debate over woman certainly does enact patriarchal ideologies of gender, and no feminist will underestimate its debilitating effects upon the lives of real women. But the debate is also inextricably intertwined with a range of other ideologies that structure social castes and classes, notions of race, morality or medicine, or such practices as courtliness and the literary, which are the two activities that interest me most in this essay (“¿QQué demandamos?”, 242).

Así, una vez establecidos los antecedentes principales del debate sobre la mujer en el siglo Xv, podemos analizar los distintos discursos que conforman nuestro corpus y su relación con las ideas comunes y predominantes sobre la mujer que se retomaron desde la Antigüedad.

\section{LAS DISPUTATIONES FILOSÓFICAS: TRIUNFO DE LAS DONAS DE JUAN Rodríguez DEL PADRóN}

En España, una de las primeras "defensas" de la mujer la constituyó el Triunfo de las donas de Juan Rodríguez del Padrón. Esta obra responde a los tratados que maldecían la condición femenina, como el Maldezir de las mujeres de Pere Torroella o el Corbacho de Alfonso Martínez de Toledo. Es uno de los primeros textos que la crítica ha considerado "profeminista", debido a que se encarga de rebatir todos los argumentos misóginos característicos de la época. Aunque, tal como lo hemos mencionado, no conviene caracterizar de "profeminista" a los textos cuya base filosófica y moral descansa en los mismos presupuestos misóginos que ya hemos expuesto, en la medida en la que el texto de Rodríguez del Padrón inaugura toda una línea de refutaciones a los argumentos expuestos por los maldicientes de las mujeres, puede considerarse un discurso de defensa.

Junto con el Tratado de defensa de las virtuosas mugeres de Diego de Varela y el Libro de las claras y virtuosas mujeres de Álvaro de Luna, el texto de Juan Rodríguez del Padrón se inserta en la querelle des femmes a modo de defensa 
de la virtud de las mujeres. El Triunfo de las donas se compone a mediados del siglo Xv en la corte de Juan II y de la reina María, a quien va dirigido el texto. Es muy probable que el texto se haya realizado por mandato de la Reina para salvaguardar la virtud y el honor de todas las cortesanas y de "la propia Reina a quien se intenta desagraviar" (Vélez, "De amor, de honor e de donas”, 156).

A diferencia de los otros textos de defensa, el Triunfo desarrolla un marco narrativo en el cual se inserta el debate y a partir del cual podemos hablar de las características retóricas de la obra. El autor protagonista se encuentra en un lugar conveniente para la reflexión sobre la pregunta “iqual sea, la muger o el hombre, más noble e de más exçelencia?” (Triunfo de las donas, 213). En este lugar se encuentra una fuente que, después de escuchar algunos de los pensamientos del protagonista en contra de las mujeres, le reprocha a través de "una 110 sorda boz, que no paresçía la mía, sonar, de las esparzidas aguas rompiendo” (Triunfo de las donas, 214). Se trata de la ninfa Cardiana en cuya voz se expresarán las cincuenta razones por las cuales las mujeres son más nobles que los hombres a manera de enseñanza para el protagonista. Si tenemos en cuenta que, normalmente, el exordium del discurso tiene como función principal conectar al público con el autor y con lo que se va a decir a continuación, tiene sentido que el autor haya escogido desarrollar un marco narrativo muy similar al de las ficciones sentimentales o pastoriles para preparar a sus lectores para la argumentación que viene después. También se constituye como marco contextual en el que se demuestran las constantes discusiones que se tenían en la época sobre el tema.

Del mismo modo, el exordium desarrolla y construye la captatio benevolentiae a través de dos recursos: por un lado, el autor se excusa de su ignorancia y su recelo de hablar sobre estos temas,

E la escusa legítima de la ignorançia, el defecto de la eloquencia e las otras por mí allegadas defensas, más indignaçión me causando que defensión, entrando en aqueste laberinto con trabajo de espíritu, pensé veer conmigo mesmo qual sería mayor ofensa: ofender a ellos con mi simple callar, o a mí, fablando desconvenible (Triunfo de las donas, 212).

y, por el otro, el autor asemeja su papel en el texto con la figura del aprendiz. Cardiana se convierte en la maestra que guiará al aprendiz durante el camino a la verdad: "Onde prinçipiando, facerte he clara la senda que al tu çiego juizio poco ante escura se demostrava” (Triunfo de las donas, 216). Que la argumentación quede en voz de Cardiana permite que el autor, debido a su ignorancia, quede disculpado en el ámbito de las damas y que, también, "se p[ueda] exonerar de responsabilidades de las razones más hirientes” (Vélez, La defensa, 96). Del 
mismo modo, en la medida en la que Cardiana se configura como la maestra, portadora de la verdad, se convierte también en una autoridad: se parte del supuesto de que no hay quien defienda mejor a las mujeres que las mujeres mismas.

La argumentación es presentada de forma dialéctica, en forma de disputatio. El oponente sería, en este caso, el "maldiçiente et vituperoso Covarcho" (Triunfo de las donas, 216) que puede hacer referencia tanto al Corbacho de Martínez de Toledo como al Corbaccio de Boccaccio. El texto puede considerarse un discurso epidíctico en cuanto es un elogio de las virtudes femeninas y al tiempo una reprobación de las actitudes del hombre. En esa medida, los argumentos estarán orientados hacia una comparación amplificatoria en la que se demuestra que la mujer resulta más virtuosa y el hombre menos.

Para la defensa, el autor retoma varios de los argumentos referidos en los tratados en contra de las mujeres y les da la vuelta: lo que se había considerado vicio en las mujeres se transforma en parte de sus virtudes. La base argumental del texto tiene su sustento en "actoridades de la divina e humana, moral e natural çiencia” (Triunfo de las donas, 216) y se configura a través de un número amplio de razones o depositiones. Las razones se presentan a través de una accumulatio que, junto a la autoridad que representa Cardiana, componen la argumentatio de la obra. Así, la fuerza de la argumentación recae no solo en las figuras retóricas utilizadas, sino también en el carácter verdadero de dichas razones, debido a que se basan en aquellas verdades inamovibles de las que hablamos en el apartado anterior: "çiertas, divinas, humanas e verdaderas, non fengidas razones" (Triunfo de las donas, 217).

Ahora bien, la mayor parte de los argumentos presentes en el texto se construyen a partir de la subversión de los distintos mitos que hemos mencionado hasta aquí: Eva, la virgen María y numerosas características que han sido asociadas a estas dos figuras. Los argumentos que desarrollan el tópico de Eva, pueden dividirse en tres, según la clasificación de Flood: argumentos de loco, materia y moralia. El argumento de loco alude a que la mujer es superior "por quanto dentro del paraíso, en conpañía de los ángeles formada, e non el onbre, que fue con las bestias en el canpo damasçeno fuera del paraíso, criado" (Triunfo de las donas, 218). Este argumento se contrapone a lo que ya se encuentra en San Ambrosio sobre el lugar de creación y su relación con la virtud: "Entonces, creado fuera del paraíso, esto es, en un lugar inferior, el hombre se considera mejor; y ella, que fue creada en un mejor lugar, el paraíso, se considera inferior" (De Paradiso, 1.4.24). ${ }^{3} \mathrm{Al}$ respecto resulta interesante la analogía que establece

\footnotetext{
${ }^{3}$ Traducción propia. El original dice: "Denique extra paradisum factus, hoc est in inferiore loco, vir melior invenitur; et illa quae in meliore loco hoc est, in paradiso facta est, inferior reperitur".
}

Medievalia 52:2, 2020, pp. 99-130 
el autor entre la creación de Adán y Eva y el nacimiento de Jesús y María: "Et si como Eva fue dentro del paraíso formada, bien así la engendradora de nuestra salud fue dentro de Jherusalém nasçida. Et segund que Adán fue del campo demasçeno, onde fue criado, traído al paraíso, bien así el nuestro fazedor fue traído del huerto a Jherusalém, onde fue acusado" (Triunfo de las donas, 238).

En cuanto al argumento de materia, Cardiana menciona que la mujer es superior por "aver seido formada de carne purificada, e non del vapor de la tierra, de la qual el onbre e los otros animales fueron criados" (Triunfo de las donas, 218). Nuevamente, este argumento se contrapone al mito respecto al que Eva era inferior a Adán pues era parte ancilar de él. El autor también aprovecha el argumento para aducir al hombre el carácter animal en cuanto al apetito y otras características que lo hacen a "las bestias más semejable" 112 (Triunfo de las donas, 218).

Este tipo de argumentos de loco, de materia (y podríamos incluir de tempore) se caracterizan por construirse a partir de la reversión de los argumentos contrarios, para así inhabilitarlos. Sin embargo, en el desarrollo de los argumentos de moralia la estrategia se hace un poco más complicada porque ya no se trata solamente de invertir el argumento contrario, sino que en varias ocasiones se hacen concesiones al argumento misógino, pero se utilizan para subrayar algunos defectos de los hombres. En otras ocasiones, los argumentos se utilizan para hacer énfasis en los valores tradicionalmente asociados a la mujer como la prudencia, el honor, la fortaleza, etc.

Por ejemplo, retomando el argumento de Aristóteles según el cual la mujer debe encargarse de cuidar las cosas del hogar, el autor afirma que la mujer es más prudente que el hombre: "los onbres deven las cosas ganar, et las mugeres salvar por guardar, el acto de la prudencia, que es el guardar, otorgando a la muger, al onbre el acto del ganar, que es de fortuna” (Triunfo de las donas, 230). El autor concede el precepto aristotélico y lo relaciona con la virtud de la prudencia. Así mismo, acepta el precepto de la debilidad física, pero lo asocia a una superioridad moral: "por quanto lo que fallesçió en las corporales fuerças, naturaleza en las del ánima, que son más exelentes, acresçentó” (Triunfo de las donas, 230). En este sentido, también llaman la atención los argumentos que giran en torno a la belleza y la vanidad de la mujer, vicio fuertemente destacado entre los detractores. Tal como afirma van Veen, el autor "no niega que las mujeres sean vanidosas, sino que justifica la conducta vanidosa de las mujeres" ("La mujer”, 469), culpando, por ejemplo, al hombre:

¿Et qual soliçitud, qual estudio nin trabajo de muger alguna en criar su beldat se puede a la cura, al deseo e al afán de los onbres por bien pareser, egualar, 
commo sea dellos la mayor occupaçión, non solamente en ver cada ora ropas de nueva guissa, mas en las fallar, toda vez pensando estarles mejor? (Triunfo de las donas, 223).

Lo mismo sucede cuando el autor menciona las virtudes de castidad y templanza que acrecientan la virtud de las mujeres por sobre los hombres y que, si en algunos momentos desfallecen, es culpa del engaño del hombre:

Et si algunas, que son en número pocas, se veen las leyes del casto pecho alguna vez traspassar, aquesto aviene por el engañoso amante, con falsa lengua e fengidas lágrimas, enbiando fuera gemidos sentibles e muy piadosos sospiros, se jura vezino a la muerte con fuerça de amor, el dormir se tirando con el manjar por algunos días, a fin que ante la constante dama con muerta faz paresçiendo, contra sí la pueda mover a piedat (Triunfo de las donas, 225-226).

La insistencia por parte del autor en las virtudes intrínsecas de la mujer como la castidad, la honestidad, la prudencia, etc., hacen pensar en el modelo de la mujer que presentaban los manuales de conducta de la época y, en ese sentido, "la esposa honesta, pendiente de sus labores como ama de casa, a la vez sumisa y complaciente, se presenta también como modelo en las obras de los defensores de las donas" (Pampín, "Las virtudes cardinales”, 270). El autor presenta en su texto algunos argumentos muy sólidos respecto a la mujer y se encarga de denunciar, por ejemplo, la envidia de los hombres que no ha permitido que las mujeres se eduquen: "E si algunas caresçen de las sciençias, esto es por enbidia que los onbres ovieron de su grand sotileza" (Triunfo de las donas, 230). Sin embargo, al mismo tiempo, el autor se encarga de subrayar las características del deber ser femenino y, en la medida en la que no se aleja de los preceptos misóginos, "ellos también, contribuyen a limitar el papel de la mujer en la sociedad” (van Veen, "La mujer”, 472).

Por supuesto, esta posición ambivalente que nos presentan textos como el Triunfo de las donas puede estar relacionada con ciertos intereses particulares de carácter económico y social. Tal como afirma Vélez, es posible que este tipo de tratados, en relación con el ambiente cortesano de la época, tuviera como fin el ascenso del autor a alguna esfera privilegiada de la corte ("De cuervos"). Es claro que exigir una defensa que tuviera repercusiones directas sobre la sociedad puede ser anacrónico y un tanto absurdo, pero lo que queda claro es que tampoco podemos caracterizar estos textos como "profeministas”, teniendo en cuenta que contienen un entramado retórico muy amplio y que pueden considerarse, siguiendo a Weiss "a literary game which was taken 
seriously in as much as it allowed writers to exercise their rhetorical skills while reeling off a commonplace list of female virtues and vices" (The Poet's Art, 115). Tampoco hay que olvidar que la retórica misma tiene un componente moral, "un cuerpo de prescripciones morales cuyo rol fin es vigilar" (Barthes, "La antigua retórica", 10). En medio de esa dualidad entre juego retórico y prescripción moral podemos ubicar al Triunfo de las donas.

\section{El DEBATE EN LOS GÉNEROS FICCIONALES: GRISEL Y MiRABELLA DE JUAN DE FloRES}

Ahora bien, el auge que representaron estos debates de defensa y vituperio supuso que empezaran a permear los demás productos escritos de la época y que sus características retóricas cambiaran y se relativizaran. Nos interesa analizar en este apartado el desarrollo y la inserción de estas disputatio filosóficas en medio de construcciones literarias como las del género sentimental. En Grisel y Mirabella de Juan de Flores encontramos un debate con características similares al Triunfo de las donas, pero que, en su relación con las demás partes de la obra y con los problemas sociales de la época, se modifica y funciona ya no como un simple ejercicio retórico, sino como una crítica a la funcionalidad misma de estos debates. Si bien la construcción del debate y los argumentos de defensa allí utilizados responden a una problemática relacionada con los supuestos del amor cortesano y, tal vez, sean una respuesta a la injusticia que suponen las leyes para las mujeres, nos encontramos, más que ante una defensa, frente a una ambigüedad respecto a la condición de la mujer que puede estar relacionada con la ambigüedad de la época.

En primer lugar, dado que el debate está inserto en medio de toda una narración, conviene analizar algunos elementos que lo enmarcan, sin dejar de lado que, aunque los debates se podrían leer como unidades independientes del relato, "hay que considerar que los debates no surgen gratuitamente, sino que la fábula da lugar a ellos y sus resultados comúnmente inciden en ésta” (von der Walde, Amor e ilegalidad, 21). La obra trata la historia de los amores de Grisel y Mirabella quienes, a pesar de las normas sociales y los decretos dispuestos por el rey — padre de Mirabella_, consuman su amor y deben pagar la culpa por desobedecer la ley que prohibía los encuentros sexuales antes del matrimonio. La historia, entonces, podría dividirse en tres partes, de acuerdo con Checa: la historia de los enamorados, el debate-juicio para buscar un culpable y su respectiva condena y, finalmente, la muerte de Torrellas ("Grisel y Mirabella"). Así, el debate estaría enmarcado por una historia 
amorosa y su resultado desencadenaría un final trágico. Sin embargo, aunque el debate ocupe un gran espacio dentro de la obra, algunos elementos propios de las demás partes de la narración, como la dedicatoria o la caracterización de algunos personajes, desarrollan algunas características retóricas que tienen relación con el debate posterior.

La dedicatoria inicial hace parte del exordium del texto. Presenta nuevamente el motivo de la captatio benevolentiae, pero a través de un mecanismo distinto. Flores dedica el libro a su amiga y menciona que el amor hacia ella fue el motivo por el cual se dio a la tarea de escribir:

vos, senyora, merezcays la pena de mi culpa, pues sta claro que sin esfuerzo vuestro yo no hozara atreuerme a tan loco ensayo. Que si por uentura (lo que no creo) algo de bien habra en ello, a vos, que se ha de dar la pena, den las gracias, pues yo desto solamente soy scriuano (Grisel y Mirabella, 514).

La responsabilidad es puesta en las manos de la amada, por lo que el autor queda excusado de cualquier culpa que suponga la obra. Adicionalmente, el autor también se excusa de su falta de experiencia y ciencia: "Esto porque si con auctoridat de sciencia de que carezco presumia hazer cosa a mi bien scusada, no mire que daua causa de publicar mis yerros y que el que no sabe la falta de mi flaco juizio la sepa” (Grisel y Mirabella, 514).

Por otro lado, el inicio de la narración caracteriza las condiciones sociales en las que se desarrolla la historia: no solo es un ambiente cortesano, sino que está gobernado por un rey que "era tanto iusto como la misma iusticia" (Grisel y Mirabella, 515). Por supuesto, estas características tendrán un peso fuerte en el debate, entre ellas que las condiciones del debate son muy comparables a un juicio, como lo veremos más adelante. Otro de los elementos que aporta el inicio de la narración es la belleza de Mirabella, que se asociará, de allí en adelante, con la muerte: "Y tan en stremo la amauan que por su causa venian a perder las vidas, tanto que la flor de la caualleria de casa del Rey su padre fenecio sus dias en esta tal guerra" (Grisel y Mirabella, 516). Es probable que el autor introduzca esta característica violenta de la belleza de Mirabella desde el comienzo como forma de generalización de la violencia que supone el amor hacia una mujer y, tal vez, tal como señala Grieve, "Flores indicates that women are more to blame than men, not because the judges say so, but because he shows Mirabella's beauty to be malevolent from the start, inspiring a violent passion" (Desire and Death, 70). Desde el comienzo de la narración, la mujer, encarnada en la figura de Mirabella, será catalogada bajo los supuestos del amor cortesano (dama excepcional, con virtudes 
excepcionales) y, a la vez, hacia la parte final, la mujer será cruel y pecadora, características que serán retomadas en el debate en forma generalizada.

Otro elemento propio de la narración que anticipa el debate entre Torrellas y Brazaida son los demás debates que están presentes en la obra. El primero de ellos se presenta entre Grisel y su amigo, que debaten sobre cuál de los dos merece más a Mirabella. Entre los temas tratados en el debate, encontramos la desdicha como parte del proceso de amor, la constancia y otros elementos propios del enamorado cortés. Sin embargo, se dan cuenta de que el debate a través de la palabra no es suficiente, por lo cual deciden pelear y decidirlo por la fuerza. Este primer debate parece anticipar la irresolución de los debates siguientes. Por ejemplo, el debate que se presenta más adelante entre Grisel y Mirabella sobre cuál de los dos merece más culpa tampoco sirve para que se llegue a un acuerdo, 116 pero sí para mostrar otros elementos del amor cortés. En este debate, Grisel vuelve a caracterizar la belleza de Mirabella como peligrosa: "Como Mirabella fuesse tan peligrosa y mas de hauer, yo me arme de tales pertrechos como quien pensasse combatir de las baxuras de la tierra a las alturas del cielo" (Grisel y Mirabella, 526). Del mismo modo, Mirabella recurre al argumento sobre el honor: "pues conocido es ser mas desonesto el oyr a las mujeres que el requestar a los hombres" (Grisel y Mirabella, 527). En general, en este debate Grisel y Mirabella adelantan varios de los argumentos que se utilizarán también en el debate principal. Tal como afirma Waley: "Grisel's claim to guilt is echoed in the same way by Brazayda's accusations against men" ("Introduction”, xlvi). Por ejemplo, Grisel se acusa a sí mismo de "maldad y porfiosos enganyos" (Grisel y Mirabella, 527) y Brazaida dirá más adelante en contra de los hombres que en ellos "puede mas vuestra maldad y porfia que nuestra virtud” (Grisel y Mirabella, 537).

Los dos pequeños debates mencionados anticipan, como ya vimos, el debate principal entre Torrellas y Brazaida. Para empezar, conviene referirse al desarrollo de estos personajes como voceros de los distintos juicios de valor respecto a los hombres y a las mujeres. Así como veíamos que en Triunfo de las donas Juan Rodríguez del Padrón usaba la voz de Cardiana como forma de disculpa del autor, en Grisel y Mirabella el recurso de los personajes históricamente reconocidos también disculpa al autor de los argumentos allí desarrollados. Sin embargo, el recurso de Flores es mucho más complejo, pues supone una relación directa con el lector de la época (al hacer uso del famoso Torrellas como personaje) y, a la vez, supone un debate serio y verosímil, teniendo en cuenta el contexto en el que se enmarca y la preparación física que supone el debate, a modo de tribunal.

El debate se configura estructuralmente como un juicio que determinará el culpable de las relaciones sexuales por fuera de la ley. Por tanto, Torrellas 
y Brazaida se configuran como defensores de su propio género: hombres y mujeres. Desde la configuración del espacio el debate es entendido como un juicio: "Y a la una parte de la sala stauan la Reyna con infantas y damas y otras donzellas que pare ver y oyr fueron iuntadas alli; y a la otra parte el Rey con grande multitud de gentes; y a la postremera grada staua Mirabella, que veya a Bra[ç] ayda por su auocada, y Torrellas con Grisel” (Grisel y Mirabella, 535).

Sin embargo, si bien el juicio se propone una defensa de cada uno de los enamorados según correspondiera, pasa de un caso particular a un caso general: "su debate implica la traslación de un problema concreto - quien es más culpable, Grisel o Mirabella - a un plano universal - el hombre o la mujer" (Checa, "Grisel y Mirabella”, 372). Esta generalización responde a la dificultad de resolución que ya nos encontrábamos en los debates menores y tiene su base en el uso no de silogismos científicos, sino de entimemas. Según Barthes, el entimema, en el sistema retórico aristotélico, es "un silogismo fundado en verosimilitudes o signos y no sobre lo verdadero y lo inmediato (como sucede con el silogismo científico) [...] a partir de algo probable, es decir, a partir de lo que el público piensa" ("La antigua retórica", 49). Otra definición de entimema que se desarrolla en la Edad Media a partir de la significación aristotélica tiene que ver con la articulación del silogismo: "un silogismo truncado por la supresión (en el enunciado) de una proposición cuya realidad parece incontestable" ("La antigua retórica”, 49), ya que apela a lo comúnmente aceptado. Así, Torrellas puede afirmar de las mujeres (en general) lo siguiente: "ni mirays honor de marido, fijos, parentes, ni amigos, ni de vos mismas - a quien mas obligades soys - ni a reuerencia de fama, ni muy menos al temor de la muerte. Mas antes todo aquello de vn tibio plazer lo posponeys, y todo se pone en oluido por solo que la voluntad se goze (ahunque sepays que a la postre lo haueys de llorar), diziendo que mas quereys plazer presente que gozo aduenidero" (Grisel y Mirabella, 541).

Teniendo en cuenta el código de honor femenino, el público puede completar el silogismo: a) las mujeres prefieren el placer inmediato por sobre su honor; b) Mirabella es mujer; c) Mirabella prefirió el placer inmediato a su honor; d) Mirabella es culpable. No es necesario que Torrellas complete su argumentación porque, al probar una premisa, el público puede completar el silogismo a partir del sentido común regido por las reglas de la época. De esta manera, el debate no se convierte en un juicio a partir de razonamientos lógicos, sino que hace uso de las normas y preceptos sobre la honra, la virtud, etc., ya establecidos en la sociedad de la época.

Que el debate esté conformado por entimemas que apelan al sentido común y a las leyes, supone que difícilmente se puede contrariar la posición de Torrellas frente a la culpabilidad de las mujeres, por lo que Brazaida, más 
allá que una defensa, solo puede reforzar dichas normas y dichos preceptos. Tal como afirma van Beysterveldt:

Hasta un grado muy elevado los argumentos de Torrellas son irrecusables porque están respaldados por un sistema normativo que era imposible cuestionar abiertamente en aquel tiempo. Dentro de estos límites, las réplicas de Braçayda, lejos de invalidar la argumentación de Torrellas, la complementan y la confirman (“Revisión de los debates", 6).

Entre los argumentos que se desarrollan en el debate se encuentra la inferioridad intelectual de la mujer, de modo que Brazaida no puede más que aceptar y considerar culpables a los hombres pues ellos conocen más que las mujeres: "Y Dios no nos puede mas demandar de aquello de quanto el sezo nos basta; que si con vosotros yguales nos fiziera en saber, estaua dudoso el debate. Mas v[u] estra malicia puede tanto que las innocentes mujeres pagan la penitencia de vuestro peccado" (Grisel y Mirabella, 549).

Esta inferioridad en cuanto a la inteligencia era una verdad absoluta que difícilmente se podía poner en duda, por lo que su defensa no puede constituirse como tal:

Brazaida no puede apelar abiertamente contra la arbitrariedad del decreto que atribuye a la mujer menos juicio que al hombre, porque esta diferencia "natural" entre los sexos era un postulado que estaba arraigado en la ideología socio-religiosa del tiempo y como tal era intocable (van Beysterveldt, "Revisión de los debates", 6).

El discurso de Brazaida se constituye, hacia el final, no como una defensa hacia las mujeres, sino como una denuncia respecto a las normas y las leyes de la época que indiscutiblemente siempre terminarían culpando a la mujer, pues no hay forma de apelar frente a un hombre verdades que han sido creadas por hombres: "porque en nuestra simplicidad no ay quien scriua en fauor nuestro; y vosotros, que teneys la pluma en la mano, pintays como quereys" (Grisel y Mirabella, 549). Así, el autor podría estar denunciando el concepto de justicia que se manejaba en la época, basado en leyes inamovibles y muy tradicionales que no tenían en cuenta la individualidad del caso, sino que, a través de generalizaciones absurdas, llegaban a resoluciones injustas. Tal como afirma von der Walde, "Flores demuestra que en asuntos pasionales es muy difícil atribuir más culpa a uno de los géneros, lo que viene a subrayar la injusticia del mismo tópico — que él desarrolla irónicamente-y quizá, en 
un nivel extratextual, la de las mismas leyes que - si bien con mayor suavidad - castigaban principalmente a la mujer" (Amor e ilegalidad, 144).

Según Lacarra es posible que Flores esté descalificando los debates que estuvieron muy en boga durante su producción literaria: "quizás intenta descalificar el debate tan en boga en su tiempo sobre la 'querelle des femmes' acusando y ridiculizando a detractores y defensores de la mujer por su duplicidad" ("Juan de Flores”, 225). Es posible que esa crítica esté basada en el uso del debate para solucionar distintos problemas que necesitarían más que argumentos "lógicos" para solucionarse. La crítica está también relacionada con el hecho de que los personajes no sean representados realmente por sus defensores: "El juicio, en lo que toca a los amantes, aparece así como algo que habrá de ser a todas luces injusto, pues los abogados, opuestos a lo que son sus defendidos, no los representan; tampoco conocen el verdadero sentir de quien, indirectamente, habrán de condenar" (von der Walde, Amor e ilegali$d a d, 129)$ y que el resultado del juicio se considere injusto e inservible pues al final mueren los dos amantes.

Esta crítica del autor a los sistemas legislativos de la época podría entenderse también a raíz del final de la obra, en una especie de "justicia poética": "law is not justice, though at its best it may point in the direction of justice. In literature, as in life, the only real justice is poetic justice, and the story of the triumph of law does not quite achieve this" (Frye, The Secular Scripture, 138). Sin embargo, ese mismo final nos permite observar la ambigüedad que supone la obra que, por un lado, puede estar justificando la toma de justicia por parte de las mujeres, pero, al mismo tiempo, parece juzgar a las mujeres como bacantes e, incluso, caníbales que, efectivamente, no pueden controlar sus pasiones y cuya acción final parecería corroborar la idea de su "natural" intemperancia.

Grisel y Mirabella podría interpretarse también como una obra misógina, cuya defensa se mantiene en los mismos presupuestos del ataque a las mujeres. Sin embargo, el final en el que Torrellas, el autor misógino por excelencia, se enamora apasionadamente de su contrincante y después termina asesinado por un grupo de mujeres como forma de venganza, convierte la obra en un texto realmente ambiguo. Esta ambigüedad puede ser consecuencia de la ambigüedad de la época que convivía aún con normas y leyes obsoletas que no se relacionaban con la realidad fáctica:

Dicho carácter se liga a la vivencia, no articulada explícita o conscientemente, de una crisis cultural e histórica que rebasa, y termina diluyendo, la efectividad de un hipotético didactismo. Desde este punto de vista, varias anfibologías o 
agujeros del relato son también índice de la situación de un escritor intermitentemente envuelto en las contradicciones del mundo que él mismo representa y que no siempre parece dominar ni comprender (Checa, "Grisel y Mirabella", 370).

Entonces, el debate sobre la culpabilidad de hombres y mujeres en la consumación del amor sin tener en cuenta las leyes estipuladas por la corte, en contraposición con comportamientos y prácticas totalmente diferentes pueden mostrarnos cuán obsoletos son la generalización y los desarrollos lógicos para hablar sobre conflictos humanos que se escapan justamente a toda conceptualización. La obra resulta, más que en una defensa o en una consolidación de los términos misóginos, en una búsqueda de un nuevo concepto de justicia que tenga en cuenta las particularidades del ser humano y su condición. Lo anterior obliga a que el debate, en este caso, no sea estudiado como único elemento en la obra de Flores, sino que deba considerarse en su relación con los demás elementos de la narración y los distintos problemas que el debate mismo refiere: la injusticia, la violencia, el amor (con los presupuestos cortesanos), las leyes, etc.

\section{LA DEFENSA NARRATIVA: GRIMALTE Y GRADISA DE JUAN DE FLORES}

Como veíamos en el apartado anterior, el debate filosófico se empieza a insertar en las narraciones ficcionales y forma parte fundamental de la estructura de la obra. Sin embargo, hay otras obras en las que, aunque el debate filosófico no esté en el centro, sigue perviviendo parte del problema argumental sobre la diferencia entre hombres y mujeres. Tanto la injuria a las mujeres como la respectiva "defensa" se presentan como parte de los diálogos entre los protagonistas sin el armazón retórico que encontrábamos en las obras anteriores: a la defensa propia de este debate desdibujado la llamaremos defensa narrativa. Cuando hablamos de defensa narrativa nos referimos, entonces, a la defensa que no está inserta en un debate retórico propiamente, sino que surge como respuesta a inculpaciones específicas dentro de la narración. Este caso lo encontramos, por ejemplo, en Grimalte y Gradisa de Juan de Flores, en donde no hay un debate como el que veíamos en Grisel y Mirabella, pero sí hay una serie de inculpaciones hacia Gradisa y un intento de defensa de su parte como respuesta inmediata a tales inculpaciones. Nos interesa terminar con este tipo de análisis para mostrar que, incluso en estos casos en donde la intención, 
más que retórica, es narrativa, se repiten algunos de los tópicos y mecanismos que ya veíamos en las dos obras anteriores.

Como veíamos, en Grisel y Mirabella la discusión principal estaba relacionada con la culpabilidad de hombres y mujeres en la consumación del acto amoroso, mientras que en Grimalte y Gradisa la discusión principal girará en torno al amor y a la forma en la que hombres y mujeres aman, pasando por temas como el honor y la constancia. Aunque los temas tengan una relación directa, la diferencia estriba en que las discusiones en Grimalte y Gradisa están en boca de los mismos protagonistas. El tema nos instala nuevamente en la querelle des femmes del siglo XV español, pero agrega un componente pasional y psicológico (que prima sobre el componente filosófico y retórico que veíamos en las dos obras anteriores) fundamental en este último texto. El tema del amor es un tema en sí mismo problemático, sobre todo en la época en la que el amor cortés se instalaba como paradigma del amor en espacios cortesanos, y en Grimalte y Gradisa nos encontramos con dos perspectivas: un requerimiento de amor en proceso (de parte de Grimalte hacia Gradisa) y un proceso de amor que ha culminado de manera infortunada (la aventura amorosa entre Fiometa y Pánfilo). Los personajes se encuentran en un padecimiento ocasionado por el amor: Grimalte debe soportar el rechazo de Gradisa y Fiometa llora el abandono y el rechazo de Pánfilo. Sin embargo, esta perspectiva emocional que nos dejan entrever Grimalte y Fiometa se contrapone a una racional en boca de Gradisa y Pánfilo. El amor, entonces, se caracteriza mediante dos perspectivas contrapuestas, la razón y la pasión, que intentan responder a una incógnita a lo largo de la obra: ¿quiénes, entre hombres y mujeres, pueden amar de una manera más adecuada?

La búsqueda de la respuesta a la pregunta central ya no se da en términos retóricos solamente, a través del desarrollo de silogismos o de debates argumentales, sino que parte, en un principio, de la experiencia de los protagonistas de la obra y, en ese sentido, se configura como un debate empírico en el que las pruebas son el testimonio de cada personaje. Sin embargo, ese testimonio se encuentra delimitado por Grimalte, el narrador. Nuevamente, tal como en las dos obras anteriores, si bien encontramos personajes femeninos que a través de su propio discurso contribuyen a la discusión y a la defensa, estos discursos están mediados por un narrador que se encarga de interpretarlos. Tal como señala Haywood, esta es la diferencia principal entre la Elegía di Madonna Fiammetta de Boccaccio (relato que retoma Flores) y Grimalte y Gradisa:

Fiammetta's world is a self-creation in which she continually describes herself and the responses she provokes. In Grimalte y Gradissa, Grimalte, like 
Fiammetta, is entirely self-portraying but the positions of the other characters are more complex: they are self-presenting through their own discourses and portrayed by others through direct discussion of their actions. This is true of Gradissa, whose voice is heard only twice and yet who is frequently referred to by Grimalte (“Gradissa: a Fictional Female”, 90).

El hecho de que el discurso de Fiometa en la obra de Flores esté mediado por Grimalte implica, desde el inicio, que su "defensa" también estará mediada por este narrador y por un punto de vista masculino. Grimalte, a pesar de hallarse en la posición desfavorable en la que lo ha situado Gradisa, es más afín ideológicamente a los postulados de Pánfilo que consideran inferior a la mujer y que, al tiempo, reprueban el comportamiento de Fiometa en su aventura amorosa, como también lo señala Franco en su ensayo "Las paradojas del amor en Grimalte y Gradissa”. Por ejemplo, como consejo a Fiometa, Pánfilo la persuade de volver a su tierra y le dice, además, "dexad de seguir vuestro apetito de mal propósito, pues éste á sido muchas veces causa de derribar las mugeres en la más baxa parte de sus honores" (Grimalte y Gradisa, 174). Sin embargo, la relación entre personajes resulta más compleja debido a que las dos parejas funcionan bajo dinámicas jerárquicas distintas: por un lado, Gradisa es la "ama" de Grimalte, lo cual le da derecho a enviarlo a intentar salvar la relación entre Pánfilo y Fiometa; por el otro, Fiometa se encuentra completamente subordinada a Pánfilo, por lo cual su desdén y rechazo le causan un gran sufrimiento. Esta dinámica de amo-esclavo, proveniente de la tradición del amor cortés, permite que en el texto se desarrolle una dinámica de reproche-defensa según la posición jerárquica que ocupe el enamorado: Pánfilo y Gradisa (los amos) pueden reprochar el comportamiento de Fiometa y Grimalte (los esclavos), respectivamente.

Esta diferencia en las jerarquías se debe al hecho de que Fiometa no siguió las reglas propias del amor cortés, mediante las cuales se dictamina que las mujeres deben prolongar el requerimiento amoroso lo más que se pueda, pues "mueran vuestros desseos primero que vuestras honras" (Grimalte y Gradisa, 181). En el momento en el que Fiometa deja de lado su honra y accede a los requerimientos de Pánfilo, las posiciones de poder cambian y los hombres toman la ventaja: "cosa justa es que las mugeres en este caso de amor no en todas cosas nos señoreen, que si presos en los fines y principios nos toviésedes, muy gran soberbia sería la de vosotras. $\mathrm{Y}<\mathrm{a}>$ sí por esto fue mejor que si en los comienços mandáis, que en los fines que seamos mandadores" (Grimalte y Gradisa, 175).

Tal como señala Albuixech: 
Vemos que mientras Gradissa, mujer castellana, retiene su vergüenza (factor que impide ser ella quien acuda en busca de Fiometa) y con ello su superioridad sobre Grimalte en la cuestión de amor, Fiometa, una italiana, pierde honra y vergüenza al acceder al trato amoroso con Pamphilo despojándose, en última instancia, del único reducto de superioridad reservado a la mujer en relación al hombre, el del terreno erótico-sentimental (“Utopía y distopía”, 187).

Ante esta inculpación, Fiometa responde de manera muy similar a la que respondía Brazaida: acepta, por un lado, su culpa e intenta justificarla. Por ejemplo, Fiometa se defiende a través del amor más puro que ella le profesa a Pánfilo: "Ni creas que yo por disolutos desseos me venço, mas el grande e limpio amor que te yo he me faze fuera de términos salir y desonestarme" (Grimalte y Gradisa, 147). Al igual que en la defensa de Brazaida, la defensa de Fiometa acepta y parte de los presupuestos que se encuentran en los reproches de Pánfilo y Grimalte. Ante el reproche de haber dejado su honor de lado, virtud principal de las mujeres de la época, Fiometa se escuda en el amor más perfecto y la mayor capacidad de amar que profesan las mujeres, tema que, por cierto, también toca Brazaida en su defensa.

Otro argumento fundamental del reproche que se le hace a Fiometa está relacionado con la falta de razón con la que aman las mujeres, lo cual convierte su amor en algo pasional y falso, lejos de cualquier actitud sana para el hombre: "Piensa agora como por la mayor parte los hombres, aunque afición nos ciega, siempre seguimos más a la razón que a deleites de la voluntad, y el más fuera de términos aficionado tiene más entero juizio para se guardar que las mugeres, ende más cuando encomiença a amar" (Grimalte y Gradisa, 150).

En ese sentido, el amor de Fiometa se percibe como una locura que ha cegado sus sentidos y la capacidad de ser consciente de sus múltiples fallas. Pánfilo se siente responsable de hacerle notar a Fiometa las faltas que ha cometido y que ha olvidado, seguramente, por su falta de razón: "Y aunque agora mi consejo sea enemigo de tus desseos, después que a tu sentido tornes, loarás lo que agora aborreces, y me serás en cargo porque tanto sobre tus honores he proveído" (Grimalte y Gradisa, 151). En esta idea de la irracionalidad femenina en comparación con la racionalidad que caracteriza el amor masculino estriba el debate principal de la obra: "Fundamentally the work, like Grisel y Mirabella, is a sort of debate between the sexes, here between man as a rational, and woman as an emotional, being, and a demonstration of their respective roles in the progress of an amour, in the empirical terms to be expected of the author of Grisel y Mirabella" (Waley, "Love and Honour", 269). 
Fiometa termina aceptando la culpabilidad de esta irracionalidad que no puede controlar: "Si aquel cruel y de mí no piadoso amor que tanto tuya me faze, templar quisiese sus llamas, con las cuales, aunque quiero, no puedo tomar templança para que la razón me aconseje" (Grimalte y Gradisa, 153). Y la única forma que encuentra para defenderse es culpando a Pánfilo, y a los hombres en general, de inconstantes, movibles y engañosos, en contraposición a la firmeza que ella ha mostrado a pesar de la deshonra que supuso:

Ya muy tarde me viene el conoscimiento de quién eres tú; no sé quién eres tú, por quien yo tales y tan altas cosas he perdido. Ni sé con qué ciegos ojos te he mirado fasta aquí que, por cierto, todo aquello en que yo agora me veo, era en aquel tiempo contigo que te amé. Y claro está de conoscer, si yo del loco amor más que de virtud no me venciera (Grimalte y Gradisa, 156).

Por supuesto estas acusaciones de Fiometa recuerdan las acusaciones que hacía Brazaida, también centradas, principalmente, en el engaño y la inconstancia. Del mismo modo, así como Brazaida se siente vencida en algún punto por el entramado legal, Fiometa se siente también vencida en algún punto, tanto que la única salida que encuentra es la muerte. La muerte de Fiometa se da en un momento en el que ya no encuentra forma de defenderse ante las acusaciones y el desdén de Pánfilo. Fiometa al final deja de defenderse y solo puede atribuirse todas las culpas y culparse ella misma por los "yerros" que la llevaron a tomar la decisión final:

¡Tú, ensuziamiento de limpio matrimonio, robadora de la honra de tu marido, no meresçedor de tus ofensas! ¡Tú, destruimiento de tu casa y de las agenas riquezas, pocas por ti ganadas y muchas con ma $<$ g $>$ nánimo coraçón en los tus vicios largos despendidos! ¡Tú, oprobio de las famosas dueñas, enxemplo de toda maldad, induzimiento de la singular, favor de malas, aborrescedora de buenas, pérdida de los espirituales bienes, entera esperança de las infernales penas, causa de lloros a tus amigos, conplido plazer de tus enemigos, sepultura de pecados, imagen de quien los haze, desonestad para el mundo y tierra que te crió! (Grimalte y Gradisa, 168).

La forma en la que Fiometa se derrumba da cuenta de la imposibilidad de encontrar una salida, una vez su honor se ha perdido, tal como sucedía con Mirabella y con la defensa a las mujeres de Brazaida. Sin embargo, su discurso final también implica un sentido moral por parte del autor que, desde el comienzo, ha hecho énfasis en la figura de Fiometa como exemplum: 
De que le siguió que ella, mirando la gran afección que le havía y la grandeza de honores que por él perdido había y, a la fin, tal paga le dava, tomó por remedio manifestar sus males a las damas enamoradas, por que en ello tomando exemplo, contra la maldad de los hombres se apercibiessen, y asimismo porque en quezar sus fatidas más senzillas las sintiesse (Grimalte y Gradisa, 90).

Esta característica toma relevancia si tenemos en cuenta el personaje de Gradisa que, aunque se mencione poco en la obra, es aquella que impulsa el viaje de Grimalte, gracias al ejemplo y la precaución que parece aprender del personaje de la obra que lee. Gradisa se contrapone a la imagen de Fiometa pues ella sí mantiene su honor y su vergüenza: "El adoctrinamiento — reiterativo- en este punto, singulariza a la mujer por su concupiscencia, como rasgo inherente a su naturaleza, y remite a un plano moral y exclusivo la volición de sus actos" (Parrilla, 48). El uso del exemplum, recurso retórico utilizado en las disputatio filosóficas de la época, en Grimalte y Gradisa se convierte en partícipe de la narración hasta el punto de que dialoga con los personajes y tiene efectos sobre sus propias decisiones. En este sentido, el recurso retórico se transforma, tal como sucede con el debate filosófico mismo, en un recurso narrativo.

Sin embargo, es interesante notar que este componente moral dentro de la obra también puede entenderse como una crítica a los conceptos sobre el amor que se tenían en la época, a través de un recorrido por los distintos males que puede acarrear tanto una forma de amar como la otra. Aquí, nuevamente, la ambigüedad de la obra no nos deja entrever una posición unívoca del autor frente al comportamiento de sus personajes. Pero, como señala Haywood, puede tratarse de "a powerful locus for the discussion of the relationships between gender, power and creation" ("Gradissa: a Fictional Female", 95).

Parece claro que la obra no se constituye como una defensa de las mujeres, del mismo modo que veíamos en los ejemplos anteriores, sino que más bien se desarrolla a partir de supuestos contrarios sobre el amor (la visión racional y la emocional). Y esta discusión puede convertirse, a su vez, en un método didáctico, tal como señala Parrilla:

Esta aparente utilidad de sus obras — didáctica servida con un evidente compromiso con la prolífica tradición de la defensa o el vituperio de la mujer-parece asegurar por su interés, una recepción moral y social de esta literatura en el marco cortesano, apto en el último cuarto del siglo xv para acoger, valorar $y$ discutir estas, en parte, instructivas ficciones (10). 
Aunque en Grimalte y Gradisa se hayan desdibujado los componentes retóricos y filosóficos para abrir paso a la narración y los distintos niveles que esta supone, es claro que la defensa que intenta Fiometa dentro de la narración también incluye componentes de los tratados y debates filosóficos que ya estudiábamos en las obras anteriores, sobre todo a nivel temático y en el uso de los personajes como exempla porque incluso narrativamente es imposible escaparse a los presupuestos ideológicos de la época. Además, el componente moral que podemos entrever hace parte de las intenciones doctrinarias $y$, posiblemente, de las intenciones de formar lectores, y se podría decir en este caso lectoras, con valores morales específicos. Aunque estas posibles intenciones están enmarcadas en distintas ambigüedades y discusiones que nos imposibilitan afirmar categóricamente cuál era el objetivo específico y real de este tipo de textos — sin dejar de lado la discusión literaria sobre el género de la novela sentimental al que posiblemente pertenecieron este tipo de debates-, es posible encontrar los mismos problemas que circunscribían las obras analizadas en los dos primeros apartados y que, por tanto, nos hace pensar en temas de interés generalizado en la época y en discusiones reales alrededor de ellos.

\section{CONSIDERACIONES FINALES}

Como hemos visto a lo largo del análisis, en los tres ejemplos que conformaron el corpus, difícilmente se puede hablar de defensa real de las mujeres, teniendo en cuenta que el entramado ideológico de la época, construido a partir de distintos mitos sobre la mujer y la condición femenina en general, imposibilitaba la creación de una defensa legítima. La defensa de la mujer en los tres casos partía de los presupuestos naturales y morales que ya desde la Antigüedad limitaron el papel de la mujer, por lo que las distintas obras se cubrían de la mismas contradicciones y ambigüedades con las que debían convivir las mujeres de la época: al tiempo que debían conservar los valores morales e ideológicos que permitían la perpetuación del orden jerárquico en la sociedad (procreación, matrimonio, sumisión, etc.), debían aceptar las inculpaciones hacia los defectos "naturales" de la condición femenina (irracionalidad, deshonor, imprudencia, etc.). Por tanto, las defensas parten siempre de una aceptación de la culpa para luego intentar dar cuenta de los defectos del otro sexo, defectos que no parecen castigarse como aquellos propios de la mujer.

El entramado retórico de los distintos discursos esconde la imposibilidad de una verdadera defensa en la sociedad que trascienda las discusiones filosóficas por parte de las élites letradas en las que difícilmente accedían y 
participaban las mujeres mismas. Y, a su vez, el hecho de que estos discursos se configuren desde las altas esferas de la sociedad permite que, de cierta forma, perpetúen un orden social y político específico, conveniente a los intereses de la sociedad patriarcal de la época, por lo que lo femenino solo aparece a través del filtro moral masculino que, ya desde los tratados doctrinales de su ideología hegemónica, prescribía lo que debía ser una mujer.

También es claro, a partir de la multiplicidad de temas y discusiones sobre la mujer, que la condición femenina resultaba un tema complejo, difícil de encasillar en una única visión del asunto, de ahí la necesidad de discutirlo desde distintos ámbitos (desde las concepciones naturalistas o médicas de Aristóteles, hasta la creación literaria de personajes femeninos, por ejemplo) y de institucionalizar aquellos mitos para que se volvieran cada vez más indiscutibles. Ante esa dificultad que representaba la mujer en la época, convenía acallar su voz y establecer normas y criterios específicos del deber ser femenino.

En general, es difícil encontrar una diferencia sustancial entre los discursos considerados misóginos o filóginos en medio de la querelle des femmes en España, más allá de una actitud más compasiva en los últimos. Podríamos pensar con lo anterior qué tipo de discursos se construyen, actualmente, en nuestra sociedad, discursos que, por un lado, ostentan un mayor entendimiento de la condición femenina, pero que pueden esconder también presupuestos misóginos legados por una tradición religiosa y filosófica. Del mismo modo, el mito de la mujer y los valores morales impuestos con el fin de conservar un orden social específico siguen vigentes en nuestra actualidad, tanto como discursos de "defensa" femeninos, que parten de los mitos mismos y que fortalecen y prolongan nuestro silencio.

\section{BibLIOGRAFÍA}

Albuixech, Lourdes, “Utopía y distopía en tres ficciones de Juan de Flores", Romania, 120:1-2, 2002, 176-191.

Ambrosius, De Paradiso. Documenta Catholica Omnia, web, 12 de octubre del 2020.

Archer, Richard, Misoginia y defensa de las mujeres. Antología de textos medievales, Madrid: Cátedra, 2001.

Archer, Richard, The Problem of Woman in Late-Medieval Hispanic Literature, London: Támesis, 2004.

Aristotle, Politica, ed. de W. D. Ross, Oxford, Clarendon Press, 1957.

Aristotle, De generatione animalium, ed. de H. J. Drossaart Lulofs, Oxford, Clarendon Press, 1965. 
Baranda, Nieves y Víctor Infantes, Narrativa popular de la Edad Media, Madrid: Akal, 1995.

BARTHES, RolAND, “La antigua retórica”, en Investigaciones retóricas I: la antigua memoria: ayudamemoria, Barcelona: Ediciones Buenos Aires, 1982.

Beysterveldt, Antony van, "Revisión de los debates feministas del siglo xv y las novelas de Juan de Flores”, Hispania, 64:1, 1981, 1-13.

Boccaccio, Giovanni, La elegía de doña Frameta; Corbacho, ed. de Pilar Gómez Bedate, Barcelona: Planeta, 1989.

Casagrande, Carla. "La mujer custodiada", en Charles Dubyy Michelle Perrot (dirs.), Historia de las mujeres, tomo II, La Edad Media, Madrid: Taurus, 2003, 93-132.

Checa, Jorge, "Grisel y Mirabella de Juan de Flores: rebeldía y violencia como síntomas de crisis", Revista Canadiense de Estudios Hispánicos, 12: 3, 1988, 369-382.

Duby, Charles y Michelle Perrot (dirs.), Historia de las mujeres, tomo II, La Edad Media, Madrid: Taurus, 2003.

Flood, John, “'Dentro del paraíso, en conpañia de los ángeles formada': Eve and the Dignity of Women in Juan Rodríguez del Padrón's Triunfo de las donas", Bulletin of Spanish Studies, 79:1, 2017, 33-43.

Flores, JuAn DE. Grimalte y Gradisa, ed. de Carmen Parrilla, Alcalá de Henares: Centro de Estudios Cervantinos, 2008.

Flores, JuAn DE, La Historia de Grisel y Mirabella, ed. de Joseph Gwara, London: University of London, 1988.

Franco VALdÉs, Brenda, “Las paradojas del amor en Grimalte y Gradissa”, en Jesús Cañas, Javier Grande y José Roso (eds.), Medievalismo en Extremadura: Estudios sobre literatura y cultura hispánicas de la Edad Media, Cáceres: Universidad de Extremadura, 2009, 1053-1064.

FrYe, Northrop, The Secular Scripture. A Study of the Structure of Romance, Cambridge: Harvard University Press, 1976.

Grieve, Patricia E., Desire and Death in the Spanish Sentimental Romance (14401550), Newark: Juan de la Cuesta, 1987.

Haywood, Louise M., “Gradissa: a Fictional Female Reader in/of a Male Author's Text”, Medium Aevum, 64:1, 1995, 85-99.

Juvenal, Sátiras, trad. de Bartolomé Segura Ramos, Madrid: Consejo Superior de Investigaciones Científicas, 1996.

Kaplisch Zuber, Christiane, "Introducción”, en Charles Duby y Michelle Perrot (dirs.), Historia de las mujeres en Occidente, tomo II, La Edad Media, Madrid: Taurus, 2003.

Lacarra, María Eugenia, "Juan de Flores y la ficción sentimental”, en Sebastián Neumeister (coord.), Actas del IX Congreso de la Asociación Internacional de Hispanistas, vol. 1, Madrid: Vervuert, 1989, 223-233. 
Lacarra, María Eugenia, "Notes on Feminist Analysis of Medieval Spanish Literature and History”, La Corónica, 17, 1988, 14-22.

LunA, Álvaro DE, Libro de virtuosas e claras mujeres, ed. de Julio Vélez-Sainz, Madrid: Cátedra, 2009.

Madrid, Mercedes, La misoginia en Grecia, Madrid: Cátedra, 1999.

Magno, Pseudo-Alberto, El De Secretis Mulierum Atribuido a Alberto Magno: estudio, edición crítica y traducción, ed. de José Pablo Barragán, Porto: Fédération internationale des instituts d'études médiévales, 2012.

Martín de Córdoba, fray, Jardín de nobles doncellas, ed. de Harriet Goldberg, Chapel Hill: University of North Carolina Press, 1974.

Martínez de Toledo, Alfonso, Arcipreste de Talavera o corbacho, ed. de Michael Gerli, Madrid: Cátedra, 1987.

Millán, Silvia, "Amazonas y lecturas de mujeres, entre la ficción y la moralidad: de la Silva de Mexía al Silves de la Selva y los Coloquios matrimoniales de Luján”, Tirant, 20, 2017, 119-146.

Olalla Real, Ángela, "Bajo el signo del doble (la mujer en los textos de agravio y defensa medievales)”, en Juan Salvador Paredes Núñez (coord.), Medioevo y Literatura: Actas del V Congreso de la Asociación Hispánica de Literatura Medieval, Granada: Universidad de Granada, 1995, 473-490.

Pampín Barral, Mercedes, "Las virtudes cardinales en el Triunfo de las donas de Juan Rodríguez del Padrón (I)”, en Mercedes Pampín Barral y Carmen Parrilla García (coords.), Actas del IX Congreso Internacional de la Asociación Hispánica de Literatura Medieval, La Coruña: Universidade da Coruña, 2005, 265-280.

Parrilla, Carmen, “Estudio introductorio”, en Juan de Flores, Grimalte y Gradisa, ed. de Carmen Parrilla, Alcalá de Henares: Centro de Estudios Cervantinos, 2008, 9-86.

Rodríguez del Padrón, Juan, Obras completas, ed. de César Hernández Alonso, Madrid: Editora Nacional, 1982.

San Pedro, Diego de, Cárcel de amor. Arnalte y Lucenda. Sermón, ed. de José Francisco Ruiz, Madrid: Cátedra, 1995.

Staley, Gregory, “'Beyond Glorious Ocean': Feminism, Myth, and America”, en Vanda Zajko y Miriam Leonard (eds.), Laughing with Medusa: Classical Myth and Feminist Thought, New York: Oxford University Press, 2006, 209-230.

Torroella, Pere, Obra completa, ed. de Robert Archer, Cosenza: Rubbetino, 2005.

Valera, Diego De, Tratado en defensa de las virtuosas mujeres, ed. de María Ángeles Suz Ruiz, Madrid: El archipiélago, 1983.

Veen, Manon van, "La mujer en algunas defensas del siglo xv: Diego de Valera y Juan Rodríguez del Padrón y los mecanismos de género", en Juan Salvador Paredes Núñez (coord.), Medioevo y Literatura: Actas del V Congreso de la Aso- 
ciación Hispánica de Literatura Medieval, Granada: Universidad de Granada, 1995, 465-474.

VÉlez-SAINZ, Julio, "De amor, de honor e de donas". Mujer e ideales corteses en la castilla de Juan II (1406-1454), Madrid: Universidad Complutense de Madrid, 2013.

VÉLEZ-SAINZ, Julio, “De cuervos y basiliscos: alegoría y corte en el 'triunfo de las donas’ de Juan Rodríguez del Padrón”, RILCE. 22:2, 2006, 259-273.

Vélez-Sainz, Julio, La defensa de la mujer en la literatura hispánica. Siglos XV-XVII, Madrid: Cátedra, 2015.

Villena, Enrique De, Obras completas, ed. de Pedro M. Cátedra, Madrid: Turner, 1994.

Walde Moheno, Lillian von der, Amor e ilegalidad. Grisel y Mirabella, de Juan de Flores, México: Universidad Nacional Autónoma de México, 1996.

Waley, Pamela, “Introduction”, Grimalte y Gradissa, London: Támesis, 1971, 1x-lxi.

WAley, Pamela, "Love and Honour in the 'Novelas sentimentales' of Diego de San Pedro and Juan de Flores”, Bulletin of Hispanic Studies, 43:4, 1966, 253-275.

Weiss, Julian, “¿Qué Demandamos de las Mugeres?’: Forming the Debate about Women in Late Medieval Spain (with a Baroque Response)", en Thelma S. Fenster y Clare A. Lees (eds.), Gender in Debate from the Early Middle Ages to the Renaissance, New York: Palgrave Macmillan, 2002, 237-274.

Weiss, Julian, The Poet's Art: Literary Theory in Castile c. 1400-60, Oxford: Medium Ævum Monographs, 1990.

Wittig, Monique, El pensamiento heterosexual y otros ensayos, Barcelona: Egales, 2006.

Xenophon, Opera omnia, vol. 2., Oxford: Clarendon Press, 1921 (repr. 1971). 